\title{
Influence of Orally Administered Probiotic Lactobacillus Strains on Vaginal Microbiota in Women with Breast Cancer during Chemotherapy: A Randomized Placebo- Controlled Double-Blinded Pilot Study
}

\author{
Julian Marschalek ${ }^{a} \quad$ Alex Farr $^{a} \quad$ Marie-Louise Marschalek $^{a} \quad$ Konrad J. Domig ${ }^{b}$ \\ Wolfgang Kneifel $^{b} \quad$ Christian F. Singer $^{a}$ Herbert Kiss $^{a}$ Ljubomir Petricevic $^{a}$ \\ a Department of Obstetrics and Gynecology, Medical University of Vienna, Vienna, Austria; \\ ${ }^{b}$ Department of Food Science and Technology, BOKU - University of Natural Resources and Life Sciences, Vienna, Austria
}

\section{Keywords}

Vaginal microbiota - Lactobacillus species .

Breast cancer · Chemotherapy · Probiotics · Nugent score

\section{Summary}

Background: Due to chemotherapy and estrogen deprivation therapy, genitourinary syndrome of menopause is a common condition in breast cancer patients. We aimed to determine the effect of an orally administered Lactobacillus preparation on the vaginal microbiota in breast cancer patients. Methods: Postmenopausal breast cancer patients receiving chemotherapy, with vaginal atrophy and an intermediate vaginal microbiota (Nugent score 4-6), were either randomized to the intervention group receiving probiotic capsules of 4 Lactobacillus species or to the control group receiving placebo twice daily for 2 weeks. Consecutive vaginal swabs were taken at baseline, 1 day after administration of the last capsule (followup 1), and after 1 week (follow-up 2) in 22 patients (11 vs. 11). Results: We observed a positive influence on the vaginal microbiota in $7 / 11$ (63\%) women in the intervention group, and 4/11 (36\%) women in the control group. There was a shift in Nugent score towards normal microbiota levels in the intervention group ( -1.3 at follow-up 1, -0.45 at follow-up 2) and a significant deterioration of the Nugent score in the control group $(+0.4$ at follow-up 1 , +2.5 at follow-up 2). Conclusion: The orally administered Lactobacillus preparation has the potential to improve the vaginal microbiota in women undergoing chemotherapy for breast cancer.

(c) 2017 S. Karger GmbH, Freiburg

\section{Introduction}

The healthy vaginal microbiota is dominated by Lactobacillus (L.) species (spp.) playing an important role in the modulation of host immune responses and the subsequent protection against genital infections. In premenopausal women, estrogen encourages the vaginal colonization with Lactobacillus spp. which metabolize glycogen to produce lactic acid and maintain a low vaginal $\mathrm{pH}$ at a level at which many pathogens cannot flourish $[1,2]$. In postmenopausal women, the genitourinary syndrome of menopause is associated with a decrease in estrogen secretion leading to a depletion of lactobacilli and an increase in vaginal $\mathrm{pH}$ followed by colonization with enterobacteria. From the clinical perspective, vaginal dryness, burning, itching, and dyspareunia are frequent complaints, along with dysuria, urinary frequency, and recurrent infections $[3,4]$.

As a result of chemotherapy and estrogen deprivation therapy, the genitourinary syndrome of menopause is a common finding among women with breast cancer (BC). The syndrome leads to symptomatic vaginal atrophy in both pre- and postmenopausal women, accompanied by cytological changes in the vaginal smear [5-7]. Vaginal estrogen therapy reduces Escherichia coli colonization and increases the number of lactobacilli, resulting in a significant decrease in recurrent urinary tract infections [8]. However, estrogen treatment for genitourinary syndrome in women with $\mathrm{BC}$ is performed with restraint since this tumor entity is often hormone-sensitive $[6,9]$. Hence, the use of lactobacilli could be a safe and effective treatment option for the prevention of bacterial dysbiosis and recurrent urinary tract infections in BC patients with genitourinary syndrome of menopause.

\section{KARGER}

(c) 2017 S. Karger GmbH, Freiburg
Ljubomir Petricevic, M.D.

Division of Obstetrics and Fetomaternal Medicine

Department of Obstetrics and Gynecology, Medical University Vienna

Waehringer Guertel 18-20, 1090 Vienna, Austria

ljubomir.petricevic@meduniwien.ac.at 
Although Lactobacillus spp. are most commonly administered through vaginal suppositories, oral substitution represents a patientfriendly concept for the restitution of a normal vaginal microbiota. In this randomized placebo-controlled double-blinded pilot study, we aimed to determine whether there is an effect of an orally administered preparation of 4 Lactobacillus spp. on the vaginal microbiota of postmenopausal BC patients undergoing chemotherapy.

\section{Patients and Methods}

From May 2014 to May 2016, all postmenopausal women with BC receiving chemotherapy at the Department of Obstetrics and Gynecology, Medical University of Vienna, Austria were invited to participate in this study. Only women without vaginal bleeding or abnormal vaginal discharge were eligible for study inclusion. Premenopausal women, women with diarrhea, constipation, or urinary tract infection, and those having received previous antibiotic therapy ( $\leq 30$ days) or any Lactobacillus spp. preparations ( $\leq 4$ weeks) were excluded from the study.

After having given oral and written informed consent, an initial vaginal smear was taken with sterile swabs from the lateral vaginal wall and posterior fornix vaginae; smears were Gram-stained and microscopically analyzed using the Nugent scoring system [10] by experienced microbiology staff specialized in gynecological cytopathology at our laboratory which is certified according to DIN EN ISO 9001:2008 (regular quality management training is compulsory for all laboratory assistants who together analyze more than 5,300 Gramstained smears per year).

The Nugent scoring system was used since it is an objective semi-quantitative evaluation of vaginal fluid. The Nugent score ranges from 0 to 10 , therewith describing a weighted combination of the following morphotypes: i) Lactobacillus spp., ii) Gardnerella vaginalis, iii) Bacteroides (small Gram-variable rods or Gram-negative rods), and iv) curved Gram-variable rods. To detect minor effects, scoring was performed using the entire 10-grade scale rather than using the simplified classification, with bacterial vaginosis being defined as a score $\geq 7$, intermediate vaginal microbiota as a score $4-6$, and normal vaginal microbiota as a score $0-3$.

Following the analysis of the initial vaginal swabs, only women with Nugent scores between 4 and 6 , defined as intermediate vaginal microbiota, were randomized to 1 of 2 study groups using a computer-generated randomization list. According to the Nugent scoring system, a Nugent score of 4-6 included smears without any bacterial colonization or Lactobacillus spp. showing only epithelial cells on the examined smears, and/or smears with colonization by mixed aerobic bacteria and depletion of lactobacilli.

Women in the intervention group received probiotic capsules containing $2.5 \times 10^{9}$ colony-forming units (CFU) each of lyophilized L. crispatus LbV 88, L. rhamnosus LbV 96, L. jensenii LbV 116 and L. gasseri LbV 150N (table 1). Administration included twice daily oral intake for 2 weeks. Women in the control group received an oral placebo containing lactose, which was also given twice daily for 2 weeks. From each participant, consecutive vaginal swabs for Nugent scoring were taken on the day following the last capsule administration and 1 week later. All participants, investigators, and microbiological staff were blinded to the treatment assignment. The Nugent score after treatment served as the primary outcome variable.

Demographic information was summarized and displayed using descriptive statistics. Continuous data are presented as mean ( \pm standard deviation (SD)) in the case of a normal distribution, or as median (interquartile range (IQR)) in the case of a skewed distribution. Discrete data are presented as number (percentage). The chi-square test was used to compare categorical data, and Student's t-test was used to compare continuous data. A 2-sided p value of $<0.05$ was considered to indicate statistical significance in all tests. Statistical calculations were performed using the statistical software SPSS 23.0 for Mac (IBM Corp., Armonk, NY, USA). The ethical review board of the Medical University of Vienna approved this study (protocol number 1417/2012; EudraCT no.
2012-003468-31; clinical trials no. NCT01723592). The study was performed in accordance with the Declaration of Helsinki and the guidelines of Good Scientific Practice, and was supported by the Head of the Institute.

\section{Results}

\section{Patients}

A total of 62 postmenopausal women met the inclusion criteria and were assessed for eligibility. Of these, 27 (43.5\%) women presented with an intermediate vaginal microbiota and were allocated

Table 1. Composition of the study medication

\begin{tabular}{ll}
\hline Composition & $\begin{array}{l}\text { Guaranteed viable cell count } \\
\text { (CFU/dose) }\end{array}$ \\
\hline $\begin{array}{ll}\text { L. crispatus LbV } 88 \text { (DSM 22566) } \\
\text { L. rhamnosus LbV 96 (DSM 22560) }\end{array}$ & $1 \times 109$ \\
L. jensenii LbV 116 (DSM 22567) & $0.2 \times 109$ \\
L. gasseri LbV 150N (DSM 22583) & $0.3 \times 109$ \\
Potato maltodextrin & \\
Insoluble dietary fiber & \\
Silicon dioxide & \\
\hline
\end{tabular}

Table 2. Baseline characteristics of the 27 study patients undergoing chemotherapy for primary breast cancer

\begin{tabular}{|c|c|c|c|}
\hline & $\begin{array}{l}\text { Intervention } \\
\text { group, } \mathrm{n}(\%) \\
\text { median (IQR) }\end{array}$ & $\begin{array}{l}\text { Control group, } \\
\mathrm{n}(\%) \\
\text { median (IQR) }\end{array}$ & $\begin{array}{l}\text { All patients, } \\
\mathrm{n}(\%) \\
\text { median (IQR) }\end{array}$ \\
\hline Patients & $11(100)$ & $11(100)$ & $22(100)$ \\
\hline Parity $^{\mathrm{a}}$ & $2(1-2)$ & $1(0-2)$ & $2(1-2)$ \\
\hline \multicolumn{4}{|l|}{ Menopausal status } \\
\hline Premenopausal & $0(0)$ & $0(0)$ & $0(0)$ \\
\hline Postmenopausal & $11(100)$ & $11(100)$ & $22(100)$ \\
\hline Nicotine abuse & $1(9.1)$ & $3(27.3)$ & $4(18.2)$ \\
\hline Alcohol abuse & $2(18.2)$ & $5(45.5)$ & $7(31.2)$ \\
\hline \multicolumn{4}{|l|}{ Affected breast } \\
\hline Left & $5(45.5)$ & $4(36.4)$ & $9(41.0)$ \\
\hline Right & $5(45.5)$ & $4(36.4)$ & $9(41.0)$ \\
\hline Bilateral & $0(0)$ & $3(27.3)$ & $3(13.6)$ \\
\hline $\mathrm{n} / \mathrm{a}$ & $1(9.1)$ & $0(0)$ & $1(4.6)$ \\
\hline \multicolumn{4}{|l|}{ Distant metastases } \\
\hline None & $6(54.6)$ & $3(27.3)$ & $9(41.0)$ \\
\hline Lung & $0(0)$ & $1(9.1)$ & $1(4.6)$ \\
\hline Liver & $0(0)$ & $3(27.3)$ & $3(13.6)$ \\
\hline Bone & $1(9.1)$ & $0(0)$ & $1(4.6)$ \\
\hline Skin & $1(9.1)$ & $0(0)$ & $1(4.6)$ \\
\hline Multiple & $3(27.3)$ & $4(36.4)$ & $7(31.2)$ \\
\hline \multicolumn{4}{|l|}{ Histology } \\
\hline Ductal & $7(63.6)$ & $9(81.8)$ & $16(72.7)$ \\
\hline Lobular & $1(9.1)$ & $0(0)$ & $1(4.6)$ \\
\hline Inflammatory & $1(9.1)$ & $1(9.1)$ & $2(9.1)$ \\
\hline Other & $1(9.1)$ & $1(9.1)$ & $2(9.1)$ \\
\hline DCIS/LCIS & $3(27.3)$ & $7(63.6)$ & $10(45.5)$ \\
\hline $\mathrm{n} / \mathrm{a}$ & $1(9.1)$ & $0(0)$ & $1(4.6)$ \\
\hline
\end{tabular}

Table 2. Continued on next page 
Table 2. Continued

\begin{tabular}{|c|c|c|c|}
\hline & $\begin{array}{l}\text { Intervention } \\
\text { group, n (\%) } \\
\text { median (IQR) }\end{array}$ & $\begin{array}{l}\text { Control group, } \\
\mathrm{n}(\%) \\
\text { median (IQR) }\end{array}$ & $\begin{array}{l}\text { All patients, } \\
\mathrm{n}(\%) \\
\text { median (IQR) }\end{array}$ \\
\hline \multicolumn{4}{|l|}{ Grading } \\
\hline G1 & $1(9.1)$ & $1(9.1)$ & $2(9.1)$ \\
\hline G2 & $4(36.4)$ & $3(27.3)$ & $7(31.2)$ \\
\hline G3 & $5(45.5)$ & $7(63.6)$ & $12(54.6)$ \\
\hline $\mathrm{n} / \mathrm{a}$ & $1(9.1)$ & $0(0)$ & $1(4.6)$ \\
\hline \multicolumn{4}{|l|}{ ER status } \\
\hline Negative & $1(9.1)$ & $6(54.6)$ & $7(31.2)$ \\
\hline Positive & $9(81.8)$ & $4(36.4)$ & $13(59.1)$ \\
\hline $\mathrm{n} / \mathrm{a}$ & $1(9.1)$ & $1(9.1)$ & $2(9.1)$ \\
\hline \multicolumn{4}{|l|}{ PR status } \\
\hline Negative & $5(45.6)$ & $6(54.6)$ & $11(50.0)$ \\
\hline Positive & $5(45.6)$ & $4(36.4)$ & $9(41.0)$ \\
\hline $\mathrm{n} / \mathrm{a}$ & $1(9.1)$ & $1(9.1)$ & $2(9.1)$ \\
\hline \multicolumn{4}{|l|}{ HER2/neu status } \\
\hline Negative & $9(81.8)$ & $2(18.2)$ & $11(50)$ \\
\hline Positive & $1(9.1)$ & $8(72.7)$ & $9(41.0)$ \\
\hline $\mathrm{n} / \mathrm{a}$ & $1(9.1)$ & $1(9.1)$ & $2(9.1)$ \\
\hline \multicolumn{4}{|l|}{ p53 status } \\
\hline Negative & $7(63.6)$ & $7(63.6)$ & $14(63.6)$ \\
\hline Positive & $3(27.3)$ & $4(36.4)$ & $7(31.2)$ \\
\hline $\mathrm{n} / \mathrm{a}$ & $1(9.1)$ & $0(0)$ & $1(4.6)$ \\
\hline Ki67 index ${ }^{a}$ & $40(20-70)$ & $40(30-40)$ & $40(30-50)$ \\
\hline \multicolumn{4}{|l|}{ Surgery } \\
\hline BCS & $3(27.3)$ & $3(27.3)$ & $6(27.33)$ \\
\hline Mastectomy & $2(18.2)$ & $2(18.2)$ & $4(18.2)$ \\
\hline $\mathrm{n} / \mathrm{a}$ & $6(54.6)$ & $6(54.6)$ & $12(54.6)$ \\
\hline SLNE & $3(27.3)$ & $0(0)$ & $3(13.6)$ \\
\hline Axillar dissection & $2(18.2)$ & $5(45.6)$ & $7(31.2)$ \\
\hline \multicolumn{4}{|l|}{ Chemotherapy } \\
\hline Neoadjuvant & $5(45.6)$ & $5(45.6)$ & $10(45.5)$ \\
\hline Adjuvant & $5(45.6)$ & $6(54.6)$ & $11(50.0)$ \\
\hline $\mathrm{n} / \mathrm{a}$ & $1(9.1)$ & $0(0)$ & $1(4.6)$ \\
\hline \multicolumn{4}{|l|}{ Regimen } \\
\hline $\mathrm{EC}+\mathrm{T}$ & $6(54.6)$ & $4(36.4)$ & $10(45.5)$ \\
\hline Paclitaxel weekly & $3(27.3)$ & $3(27.3)$ & $6(27.3)$ \\
\hline FEC & $2(18.2)$ & $1(9.1)$ & $3(13.6)$ \\
\hline Platinum-based & $0(0)$ & $0(0)$ & $0(0)$ \\
\hline Gemcitabine & $0(0)$ & $2(18.2)$ & $2(9.1)$ \\
\hline TDM1 & $0(0)$ & $1(9.1)$ & $1(4.6)$ \\
\hline
\end{tabular}

${ }^{\mathrm{a}}$ Data presented as $\mathrm{n}(\%)$ if not otherwise stated or as median (IQR). $\mathrm{IQR}=$ Interquartile range; $\mathrm{n} / \mathrm{a}=$ not available; DCIS/LCIS = ductal/lobular carcinoma in situ; $\mathrm{ER}$ = estrogen receptor; $\mathrm{PR}$ = progesterone receptor; $\mathrm{BCS}=$ breast-conserving surgery; SLNE = sentinel lymphonodectomy; EC+T = epirubicin, cyclophosphamide, followed by docetaxel; FEC $=5$-fluorouracil, epidoxorubicin, cyclophosphamide; TDM1 = trastuzumab-emtansine. to the study groups. Study participants were randomized to the following study groups: 14 (51.9\%) women to the intervention group receiving an orally administered Lactobacillus spp. preparation, and $13(48.1 \%)$ women to the control group receiving a placebo. Due to loss to follow-up $(\mathrm{n}=2)$ or discontinuation of treatment ( $\mathrm{n}$ $=3$ ), a final number of 22 patients ( $\mathrm{n}=11$ in each group) were analyzed.

The median age of the women at the time of study inclusion was 59 years (IQR, 53-69 years) in the intervention group, and 62 years (IQR, 50-77 years) in the control group. Sociodemographic and BC-related patient characteristics are provided in table 2.

\section{Vaginal Smears}

Analysis of the initial screening smears revealed significant differences with respect to the Nugent score at baseline. Women in the intervention group showed a mean (SD) Nugent score of 4.73 $( \pm 1.01)$, whereas those in the control group had a mean (SD) Nugent score of $4.0( \pm 0.0)(p=0.038)$.

There was a trend towards an improvement in Nugent score in the intervention group following the administration of oral probiotics. In 7/11 (63\%) women in the intervention group, and 4/11 (36\%) women in the control group, the Nugent score indicated a change towards a normal vaginal microbiota (i.e., Nugent score of 0-3).

When analyzing the difference between the Nugent score at baseline and after treatment among women in the intervention group, we observed a mean reduction of -1.3 at follow-up visit 1 , and -0.57 at follow-up visit 2 .

Women in the control group presented with an increase in $\mathrm{Nu}$ gent score from baseline to follow-up visit 1 by +0.45 . At follow-up visit 2 , the smears of the women in the control group revealed a significant increase of +2.5 . The observed changes in Nugent scores from baseline to the follow-up visits are presented in table 3 . Neither the women in the intervention group nor those in the control group reported any adverse events throughout the study period.

\section{Discussion}

In this randomized placebo-controlled double-blinded pilot study, we were able to determine a trend towards an improvement in Nugent score through an orally administered Lactobacillus spp. preparation in postmenopausal BC patients undergoing chemotherapy. The absence of vaginal Lactobacillus spp. in the interme-
Table 3. Detailed Nugent scores at baseline, follow-up 1, and follow-up 2 in the intervention and the control group

\begin{tabular}{|c|c|c|c|c|c|}
\hline & \multirow{2}{*}{$\frac{\text { Baseline }}{\text { Nugent }}$} & \multicolumn{2}{|l|}{ Follow-up 1} & \multicolumn{2}{|l|}{ Follow-up 2} \\
\hline & & Nugent & $\mathrm{p}$ value & Nugent & $\mathrm{p}$ value \\
\hline Intervention group ${ }^{\mathrm{a}}$ & $4.73( \pm 1.01)$ & $3.27( \pm 2.15)$ & & $4.00( \pm 3.27)$ & \\
\hline$\Delta$ from baseline & - & -1.30 & 0.084 & -0.57 & 0.751 \\
\hline Control groupa & $4.00( \pm 0.0)$ & $4.45( \pm 2.25)$ & & $6.50( \pm 1.73)$ & \\
\hline$\Delta$ from baseline & - & +0.45 & 0.473 & +2.50 & $<0.001$ \\
\hline
\end{tabular}

${ }^{a}$ Data are presented as mean ( \pm standard deviation). $\Delta=$ Difference. 
diate vaginal microbiota has shown to be a pathological condition rather than a simple deficiency [11]. Due to chemotherapy and estrogen deprivation therapy, $\mathrm{BC}$ patients have an increased risk for absence of and reduction in vaginal lactobacilli [5-7]. In this cohort, treatment with lactobacilli constituted a safe and effective option for the prevention of bacterial dysbiosis, infection, and symptomatic genitourinary syndrome $[6,9]$.

The most common way of Lactobacillus spp. substitution is the administration of vaginal suppositories. Nevertheless, oral administration represents an alternative and patient-friendly concept for the restitution of a normal vaginal microbiota. The fundamental theory is based on studies that have found a connection between the colonization of the gastrointestinal and genitourinary tract by Lactobacillus spp., showing that the gut may serve as a reservoir for vaginal colonization by lactobacilli for the maintenance of a normal vaginal microbiota [12-14]. Morelli et al. [15] demonstrated by polymerase chain reaction amplification that certain Lactobacillus spp. could be delivered to the vaginal microbiota when administered orally. In 2008, our study group was able to demonstrate a significant change in the vaginal microbiota with an increased presence of Lactobacillus spp. after oral administration of probiotic Lactobacillus spp. preparations [16].

Evidence suggests that there is a notable geographic variation in the composition of the normal microbiota of the vagina [17-19]. Vásquez et al. [17] found that this microbiota is dominated by a single Lactobacillus spp. in most women, with a broad individual variability regarding the presence of other species. In one of our previous studies, we were able to report that $L$. crispatus and $L$. gasseri are the most frequent species in the vagina of pregnant women, followed by L. jensenii and L. rhamnosus [19]. Moreover, we successfully tested probiotic capsules containing these species and reported an improvement in the vaginal Lactobacillus microbiota after oral administration in male-to-female transsexual women [20].

In the present study, we were able to demonstrate that the genitourinary syndrome of menopause and symptomatic vaginal atrophy are common findings among women with $\mathrm{BC}$ undergoing chemotherapy. This stands in accordance with the currently available literature [5-7]. Moreover, we found that the Nugent score of these patients could be improved through the intake of oral probiotics. According to our data, Nugent scores increased after only 1 week following the final administration. This leads us to hypothesize that the protective effect of orally administered lactobacilli on the vaginal microbiota ends with the discontinuation of the treatment in postmenopausal women. The finding that Nugent scores increased by +2.5 from baseline to follow-up 2 in untreated women may support this theory.
As a result of the widespread use of probiotics, some studies have questioned their safety, postulating a possible correlation between the intake of lactobacilli and adverse events [21-24]. Considering the risk of systemic bacteremia, immunocompromised patients in particular were regarded as suboptimal candidates for probiotic treatments. However, evidence for safety was derived from studies that safely administered probiotic strains to this specific patient population $[22,24]$. Our study again confirms these data since we did not observe any adverse events in our study cohort, only a positive effect on the vaginal microbiota of our immunocompromised cancer patients. This stands in accordance with data of a systematic review that evaluated the results of 53 trials, which found basically no negative effect on safety outcomes regarding infectious adverse events [21].

We are aware of the fact that the sample size of our study was very small, and therefore our results need to be interpreted with caution. In light of the fact that our data form a pilot study, further studies are urgently needed to assess the improvement in Nugent score in this setting. We admit that our study population might have been too small to reach statistical significance within the analyses, and clearly the observed effect failed to reach the level of statistical significance by the end of this observation. However, we noticed a positive trend toward improvement in Nugent score during the therapy. This opens up a new discussion about the duration of treatment with probiotics during chemotherapy. Of note, it was relatively difficult to motivate women undergoing chemotherapy to participate in a study such as this.

In conclusion, this randomized placebo-controlled doubleblinded pilot study found an improved Nugent score after the administration of an orally administered Lactobacillus preparation in postmenopausal BC patients undergoing chemotherapy, whereas the score deteriorated without treatment. This lends support to the idea that the tested probiotic preparation has the potential to improve the vaginal microbiota of affected cancer patients. According to our data, probiotics should be applied during chemotherapy in order to increase the lactobacillary level in the vagina, as well as to decrease symptomatic vaginal atrophy. As probiotic treatment could potentially prevent the development of genitourinary syndrome in postmenopausal women with $\mathrm{BC}$ and subsequent bacterial dysbiosis, further research in larger cohorts is highly warranted to confirm our findings.

\section{Disclosure Statement}

The authors declare that they have no conflict of interest in connection with this article. 


\section{References}

1 Reid G, Cook RL, Bruce AW: Examination of strains of lactobacilli for properties that may influence bacterial interference in the urinary tract. J Urol 1987;138:330335.

2 Erickson KL, Hubbard NE: Probiotic immunomodulation in health and disease. J Nutr 2000;130:403S-409S.

3 Portman DJ, Gass ML; Vulvovaginal Atrophy Terminology Consensus Conference Panel: Genitourinary syndrome of menopause: new terminology for vulvovaginal atrophy from the International Society for the Study of Women's Sexual Health and the North American Menopause Society. Maturitas 2014;79:349-354.

4 Pandit L, Ouslander JG: Postmenopausal vaginal atrophy and atrophic vaginitis. Am J Med Sci 1997;314: 228-231.

5 Sturdee DW, Panay N; International Menopause Society Writing Group: Recommendations for the management of postmenopausal vaginal atrophy. Climacteric 2010;13:509-522.

6 6 Donders G, Bellen G, Neven P, Grob P, Prasauskas V, Buchholz S, Ortmann O: Effect of ultra-low-dose estriol and lactobacilli vaginal tablets $\left(\right.$ Gynoflor ${ }^{\circledR}$ ) on inflammatory and infectious markers of the vaginal ecosystem in postmenopausal women with breast cancer on aromatase inhibitors. Eur J Clin Microbiol Infect Dis 2015;34:2023-2028.

7 Krychman ML, Carter J, Aghajanian CA, Dizon DS Castiel M: Chemotherapy-induced dyspareunia: a case study of vaginal mucositis and pegylated liposomal doxorubicin injection in advanced stage ovarian carcinoma. Gynecol Oncol 2004;93:561-563.

8 Raz R, Stamm WE: A controlled trial of intravaginal estriol in postmenopausal women with recurrent urinary tract infections. N Engl J Med 1993;329:753-756.
Krychman ML, Katz A: Breast cancer and sexuality: multi-modal treatment options. J Sex Med;9:5-13; quiz $14-15$.

10 Nugent RP, Krohn MA, Hillier SL: Reliability of diagnosing bacterial vaginosis is improved by a standardized method of gram stain interpretation. J Clin Microbiol 1991;29:297-301.

11 Farr A, Kiss H, Hagmann M, Machal S, Holzer I, Kueronya V, Husslein PW, Petricevic L: Role of Lactobacillus species in the intermediate vaginal flora in early pregnancy: a retrospective cohort study. PLoS One 2015;10:e0144181.

12 Reid G, Bruce AW, Fraser N, Heinemann C, Owen J, Henning B: Oral probiotics can resolve urogenital infections. FEMS Immunol Med Microbiol 2001;30:4952.

13 Petricevic L, Domig KJ, Nierscher FJ, Krondorfer I, Janitschek C, Kneifel W, Kiss H: Characterisation of the oral, vaginal and rectal Lactobacillus flora in healthy pregnant and postmenopausal women. Eur J Obstet Gynecol Reprod Biol 2012;160:93-99.

14 Antonio MA, Rabe LK, Hillier SL: Colonization of the rectum by Lactobacillus species and decreased risk of bacterial vaginosis. J Infect Dis 2005; 192:394-398.

15 Morelli L, Zonenenschain D, Del Piano M, Cognein P: Utilization of the intestinal tract as a delivery system for urogenital probiotics. J Clin Gastroenterol 2004; 38:S107-110.

16 Petricevic L, Unger FM, Viernstein H, Kiss H: Randomized, double-blind, placebo-controlled study of oral lactobacilli to improve the vaginal flora of postmenopausal women. Eur J Obstet Gynecol Reprod Biol 2008; 141:54-57.
17 Vasquez A, Jakobsson T, Ahrne S, Forsum U, Molin G: Vaginal lactobacillus flora of healthy Swedish women. J Clin Microbiol 2002;40:2746-2749.

18 Reid G, McGroarty JA, Tomeczek L, Bruce AW: Identification and plasmid profiles of Lactobacillus species from the vagina of 100 healthy women. FEMS Immunol Med Microbiol 1996;15:23-26.

19 Kiss H, Kogler B, Petricevic L, Sauerzapf I, Klayraung S, Domig K, Viernstein H, Kneifel W: Vaginal Lactobacillus microbiota of healthy women in the late first trimester of pregnancy. BJOG 2007;114:1402-1407.

20 Kaufmann U, Domig KJ, Lippitsch CI, Kraler M, Marschalek J, Kneifel W, Kiss H, Petricevic L: Ability of an orally administered lactobacilli preparation to improve the quality of the neovaginal microflora in male to female transsexual women. Eur J Obstet Gynecol Reprod Biol 2014;172:102-105.

21 Whelan K, Myers CE: Safety of probiotics in patients receiving nutritional support: a systematic review of case reports, randomized controlled trials, and nonrandomized trials. Am J Clin Nutr 2010;91:687-703.

22 Bernardeau M, Vernoux JP, Henri-Dubernet S, Gueguen M: Safety assessment of dairy microorganisms: the Lactobacillus genus. Int J Food Microbiol 2008 126:278-285.

23 Salminen MK, Tynkkynen S, Rautelin H, Saxelin M, Vaara M, Ruutu P, Sarna S, Valtonen V, Jarvinen A: Lactobacillus bacteremia during a rapid increase in probiotic use of Lactobacillus rhamnosus GG in Finland. Clin Infect Dis 2002;35:1155-1160.

24 Snydman DR: The safety of probiotics. Clin Infect Dis 2008;46:S104-S111. 